\title{
FORMULASI SEDIAAN SPRAY DAUN DAN BATANG SERAI WANGI (Cymbopogon nardus L.) SEBAGAI ANTINYAMUK Culex s.p
}

\section{FORMULATION OF THE SPRAY LEAVES AND CITRONELLA STEMS (Cymbopogon nardus L.) AS REPELLENTS OF THE Culex S.p MOSQUITO}

\author{
La Ode Akbar Rasydy ${ }^{1 *}$, Banu Kuncoro ${ }^{1}$, Muhammad Yusuf Hasibuan ${ }^{1}$ \\ ${ }^{1}$ Sekolah Tinggi Farmasi Muhammadiyah Tangerang \\ ${ }^{*}$ Corresponding Author Email: akbar rasidy@yahoo.com \\ DOI: http://dx.doi.org/10.47653/farm.v7i1.150
}

\begin{abstract}
ABSTRAK
Daun dan Batang serai wangi (Cymbopogon nardus L.) merupakan tanaman yang memiliki kandungan geraniol dan sitronelal yang berfungsi sebagai antinyamuk. Penelitian ini bertujuan untuk memformulasikan sediaan spray antinyamuk dari tanaman serai wangi (Cymbopogon nardus L.) dengan menggunakan metode destilasi yang akan diujikan terhadap aktivitas nyamuk Culex s.p. Bahan yang digunakan dalam pembuatan spray adalah minyak atsiri daun dan batang serai wangi (Cymbopogon nardus L.) dengan variasi konsentrasi 0\%, 5\%,10\% dan 15\%. Semua formula sediaan spray diuji stabilitas meliputi ( $\mathrm{pH}$ dan viskositas) serta efektivitas terhahap nyamuk Culex s.p. Dari hasil pengujian $\mathrm{pH}$ dan viskositas menunjukan bahwa $\mathrm{pH}$ sesuai dengan standar $\mathrm{pH}$ pada kulit dan memiliki viskositas yang cukup baik. Hasil dari efektifitas sediaan spray menyatakan bahwa pada sediaan spray dengan konsentrasi ekstrak $15 \%$ memiliki daya tolak nyamuk yang cukup efektif.
\end{abstract}

Kata Kunci: Spray Antinyamuk, Minyak Atsiri Serai Wangi (Cymbopogon nardus L.), Nyamuk Culex s.p

\section{ABSTRACT}

The leaves and stems of lemongrass (Cymbopogon nardus L.) are plants that contain geraniol and Citronelal that serve as mosquito repellent. This study to formulate anti mosquito spray preparation of the fragrant lemongrass plant (Cymbopogon nardus L.) using the distillation method that will be tested against the activity of mosquito Culex s.p. materials used in the manufacture of spray are essential oil of lemongrass leaves and stems (Cymbopogon nardus L.) with varying concentrations of 0\%, 5\%, $10 \%$ and $15 \%$. All spray preparations formula test stability including $\mathrm{pH}$ and viscosity and effectiveness of mosquitoes Culex s.p. From the test results $\mathrm{pH}$ and viscosity indicated the $\mathrm{pH}$ corresponds to the $\mathrm{pH}$ standard on the skin and had a fairly good viscosity. The result of the effectiveness of spray preparations stated that on the preparation of spray with concentration of extracts $15 \%$ had a mosquito repellent with quite effective.

Keywords: Mosquito Repellent Spray, Lemongrass Scented Essential Oil (Cymbopogon Nardus L.), Culex s.p Mosquitoes

\section{PENDAHULUAN}

Nyamuk merupakan serangga yang banyak kita jumpai peranannya sebagai vektor penyakit-penyakit berbahaya bagi manusia misalnya penyakit kaki gajah, malaria dan demam berdarah dengue (Susanti \& Boesri 2012). Pengendalian terhadap nyamuk sebagai vektor penyakit banyak dilakukan yaitu dengan cara menurunkan populasi atau dengan memutus siklus hidupnya (Andriani, 2008). Diantaranya dengan menggunakan antinyamuk kimia sintetis seperti diethyltoluamide (DEET), diclorovinil dimethyl phospat (DDP) malathion, parathion, dan lainlain penggunaan bahan kimia tersebut secara terus menerus, selain berdampak buruk terhadap kesehatan manusia, juga akan membuat nyamuk resisten (Kardinan \& Dhalimi, 2010).

Upaya mengurangi penggunaan bahan kimia sintetik pada nyamuk, sangatlah bijak bila mengoptimalkan penggunaan tumbuhan 
yang mempunyai kemampuan insektisida alami terutama bagi nyamuk. Serai wangi mengandung komponen minyak-minyak menguap (volatile oil) yang biasa disebut minyak atsiri. Minyak atsiri Serai wangi mengandung 3 komponen utama yaitu sitronelal, sitronelol dan geraniol (Sastrohamidjo, 2004).

Pada penelitian sebelumnya Rofirma Manurung, indra Chahaya dan Surya Dharma yang berjudul "Pengaruh Daya Tolak Perasan Serai Wangi (Cymbopogon nardus) Terhadap Gigitan Nyamuk Aedes aegypti” dari hasil penelitian yang telah dilakukan dapat disimpulkan serai wangi menghasilkan minyak atsiri serai wangi (Citronella Oil) yang mempunyai kegunaan sebagai anti nyamuk. Jadi berdasarkan data tersebut peneliti tertarik untuk membuat penelitian tentang "Formulasi Sediaan Spray Daun dan Batang Serai Wangi (Cymbopogon nardus L.) sebagai antinyamuk Culex s.p".

Tujuan yang ingin diperoleh dari penelitian ini adalah untuk mendapatkan formulasi Spray Antinyamuk Culex s.p Minyak Atsiri Serai Wangi yang efektif, mengetahui konsentrasi Minyak Atsiri Serai Wangi yang efektif sebagai antinyamuk Culex s.p. Dan untuk mengetahui pengaruh variasi konsentrasi Minyak Atsiri Serai Wangi terhadap sifat fisik Spray.

\section{METODE PENELITIAN}

\section{Alat}

Alat yang digunakan dalam penelitian ini adalah seperangkat alat destilasi uap yang di gunakan oleh pihak Balai Penelitian Tanaman Rempah dan Obat (BALITRO), timbangan analitik, lumpang dan alu, wadah spray, alat-alat gelas laboratorium, pengaduk, viscometer (Lamy Rheologi, Francis) dan pH meter.

\section{Bahan}

Minyak Atsiri Serai Wangi (Cymbopogon nardus $L$ ) yang diperoleh dari Balai Penelitian Tanaman Rempah dan Obat (BALITRO), Propilen glikol (brataco), Etanol (Indo Acidatama), Aquadest.

\section{Cara Kerja}

Penelitian ini merupakan jenis penelitian experimen di mana penelitian ini berinteraksi dengan objek penelitian yaitu nyamuk Culex s.p serta melakukan evaluasi fisik pada Spray dan uji efektivitas terhadap nyamuk Culex s.p. pengambilan data dengan data primer dan data sekunder, yang termasuk data primer dalam penelitian ini adalah data yang di peroleh dari hasil pengamatan evaluasi sediaan spray dan uji efektivitas anti nyamuk di dalam percobaan. data sekunder dalam penelitian adalah data pendukung yang di peroleh dari studi pustaka yang berasal dari naskah publikasi, buku, dan hasil penelitian sebelumnya yang mendukung penelitian ini.

\section{Penyiapan Simplisia}

Daun dan Batang Serai wangi (Cymbopogon nardus L.) yang telah di dapat, di bersihkan dan di potong kemudian dikeringkan dengan cara di angin anginkan, lalu di jemur dibawah sinar matahari selama 12 jam dengan ditutupi kain hitam. Setelah kering, serai wangi di timbang berat massa.

\section{Proses Destilasi Minyak Atsiri Serai Wangi (Cymbopogon nardus L.)}

Pembuatan minyak atsiri serai wangi (Cymbopogon nardus L.) umumnya dilakukan dengan pelarut menguap (solvent extraction). Prinsip metode ekstrakasi dengan pelarut menguap adalah melarutkan minyak atsiri didalam bahan pelarut organic. Tahapan selanjutnya yaitu mempersiapkan serai wangi (Cymbopogon nardus L.) yang sudah disortasi basah masukkan daun dan batang serai wangi kedalam katel dan rendam menggunkan air (aquadest), lakukan destilasi di dalam evaporator vakum pada suhu $100^{\circ} \mathrm{C}$, pelarut akan menguap dan menyisakan larutan semi padat berwarna merah kecoklatan yang disebut conicenrate (Rusli, 2010).

\section{Formulasi}

Tabel 1. Formulasi

\begin{tabular}{|c|c|c|c|c|c|c|}
\hline Bahan & $\begin{array}{c}\text { F1 } \\
(0 \%)\end{array}$ & $\begin{array}{c}\text { F2 } \\
(5 \%)\end{array}$ & $\begin{array}{c}\text { F3 } \\
(10 \%)\end{array}$ & $\begin{array}{c}\text { F4 } \\
(15 \%)\end{array}$ & $K(+)$ & Fungsi \\
\hline $\begin{array}{l}\text { Minyak } \\
\text { Atsiri } \\
\text { (gram) }\end{array}$ & - & $0,5 \mathrm{ml}$ & $1 \mathrm{ml}$ & $\begin{array}{l}1,5 \\
\mathrm{ml}\end{array}$ & & Zat Aktif \\
\hline $\begin{array}{l}\text { Propilen } \\
\text { Glikol }\end{array}$ & $2 \mathrm{ml}$ & $2 \mathrm{ml}$ & $2 \mathrm{ml}$ & $2 \mathrm{ml}$ & & Kosolven \\
\hline $\begin{array}{l}\text { Etanol } \\
96 \% \\
\text { Ad10 ml }\end{array}$ & $\begin{array}{l}\text { Ad10 } \\
\mathrm{ml}\end{array}$ & $\begin{array}{c}\text { Ad } 10 \\
\mathrm{ml}\end{array}$ & $\begin{array}{c}\text { Ad } 10 \\
\mathrm{ml}\end{array}$ & $\begin{array}{c}\text { Ad } 10 \\
\mathrm{ml}\end{array}$ & & Pembawa \\
\hline
\end{tabular}




\section{Pembuatan Formula}

Pertama-tama masukkan minyak atsiri kedalam labu takar tambahkan propilenglikol untuk melarutkan, setelah larut masukkan kedalam wadah spray yang telah di kalibrasi kemudian tambahkan etanol 96\% Ad $10 \mathrm{ml}$.

\section{Sterilisasi Alat}

Wadah spray, alat-alat gelas laboratorium, dan pengaduk dilapisi dengan kerta alumunium foil kemudian dimasukan kedalam autoklaf selama 15 menit dengan suhu $121^{\circ} \mathrm{C}$.

\section{Analisa Data}

Data yang diperoleh dalam penelitian ini selanjutnya dianalisis secara deskriptif dan data disajikan dalam bentuk tabel dan grafik disertai dengan narasi. Pengujian sediaan spray sebagai berikut :

1. Pengukuran $\mathrm{pH}$ dari formula spray yang telah dibuat menggunakan $\mathrm{pH}$ universal yang dilakukan selama 7 hari, $\mathrm{pH}$ yang baik untuk kulit ialah 4,5 - 7 (R. et al., 2014).

2. Penentuan viskositas dilakukan dengan menggunakan viskometer Lamy Rheologi (Dirtjen POM, 1979).

3. Uji iritasi dilakukan dengan cara bahan tersebut dioleskan pada lengan atas bagian dalam para sukarelawan selama 1 hari.

4. Uji pembentukan busa juga menjadi salah satu parameter kualitas dari suatu larutan emulsi. Volume busa yang terbentuk menjadi tolak ukur dalam pengujian (Arif Prasetyo, 2011).

5. Uji Daya Tolak Nyamuk Pengujian dilakukan dengan menggunakan kurungan berukuran panjang $40 \mathrm{~cm}$, lebar $35 \mathrm{~cm}$, dan tinggi $40 \mathrm{~cm}$ yang berisi 25 ekor nyamuk dewasa (umur 2-5 hari, betina dan jantan, belum menghisap darah). Kurungan terbuat dari jaring berbingkai kayu. Pada sisi bagian depan terdapat 2 lubang untuk memasukan tangan dan diberi jaring sepanjang $\pm 30 \mathrm{~cm}$. Penelitian ini menggunakan spray minyak atsiri dengan konsentrasi $0 \%, 5 \%, 10 \%$ dan $15 \%$. Diujikan pada nyamuk Culex s.p. Pengujian dilakukan dengan memasukan lengan kedalam kandang uji selama 5 menit, setiap 1 jam sekali dan dilakukan berulang terhadap seluruh formulasi selama 6 jam. Uji efikasi ditetapkan berdasarkan persen penolakan nyamuk terhadap lengan uji yang menggunakan produk antinyamuk spray, dan dibandingkan dengan lengan kontrol yang tidak menggunakan apapun (Arif Prasetyo, 2011). Daya Tolak Nyamuk (Daya Proteksi) ditentukan berdasarkan daya proteksi yang dihitung dengan rumus:

$$
\text { Daya Proteksi }=\frac{K-R}{K} \times 100 \%
$$

$$
\begin{aligned}
& \text { Keterangan : } \\
& \mathrm{K}=\text { Jumlah nyamuk yang hinggap pada } \\
& \text { lengan kontrol (-) } \\
& \mathrm{R}=\text { Jumlah nyamuk yang hinggap pada } \\
& \text { lengan uji (formula) (Kardinan, } \\
& 2003) .
\end{aligned}
$$

\section{HASIL DAN PEMBAHASAN}

Tanaman serai wangi yang digunakan dalam penelitian ini yaitu bagian batang dan daun yang masih segar yang nantinya akan dicuci dan kemudian di keringkan selama 1-2 jam sebanyak $10 \mathrm{~kg}$, yang diperoleh dari perkebunan yang berada di Balai Penelitian Tanaman dan Rempah Obat (BALITTRO) dan pembuatan minyak atsiri Serai Wangi ini dilakukan di balai penelitian tersebut dengan metode penyulingan (destilasi).

Pada tabel 1. Formulasi Berdasarkan pada bahwa minyak atsiri serai wangi berfungsi sebagai pengusir nyamuk, dengan menambahkan propilenglikol yang berfungsi untuk menambah kelarutan minyak atsiri kemudian menambahkan etanol 96\% yang berfungsi sebagai zat pembawa. Proses pembuatan sediaan spray minyak atsiri serai wangi ini mengikuti acuan yang telah dilakukan oleh (Resmi aini dan Rina widiastuiti, 2016). Konsentrasi minyak atsiri serai wangi dengan konsentrasi $0 \%, 5 \%, 10 \%$ dan $15 \%$ sehingga pembuatan spray pada penelitian ini dengan menggunakan konsentrasi yang bervariasi sehingga menghasilkan formula sediaan yang berbeda-beda sebagai blanko dibuat tanpa penambahan minyak atsiri. Dimana penelitian sebelumnya pada konsentrasi $10 \%$ dapat mengusir nyamuk (Wahyunigtyas, 2004).

\section{Uji pH Formula Spray Antinyamuk}

Nilai $\mathrm{pH}$ rata-rata dari produk antinyamuk yang dihasilkan berdasarkan masing-masing formulasi yang dibuat dapat dilihat dari tabel berikut. 
Tabel 2. Hasil Uji pH Sediaan Spray

\begin{tabular}{llcccc}
\hline $\begin{array}{c}\text { N } \\
\text { o }\end{array}$ & Formula & $\begin{array}{c}\text { Minggu } \\
\text { ke-1 }\end{array}$ & $\begin{array}{c}\text { Minggu } \\
\text { ke-2 }\end{array}$ & $\begin{array}{c}\text { Minggu } \\
\text { ke-3 }\end{array}$ & $\begin{array}{c}\text { Minggu } \\
\text { ke-4 }\end{array}$ \\
\hline 1 & F1 0\% & 7 & 7 & 7 & 7 \\
2 & F2 5\% & 6 & 6 & 6 & 6 \\
3 & F3 10\% & 6 & 6 & 6 & 6 \\
4 & F4 15\% & 6 & 6 & 6 & 6 \\
5 & $\begin{array}{l}\text { Kontrol } \\
\text { positif }\end{array}$ & 6 & 6 & 6 & 6 \\
\hline
\end{tabular}

Pada tabel 2. Pengukuran $\mathrm{pH}$ dilakukan dengan menggunakan $\mathrm{pH}$ indikator MachereyNagel, dari keempat formula tidak mengalami perubahan yang begitu signifikan dan hal ini sesuai dengan pH SNI 06-6989 11-2004 pada kulit yaitu 4,5-7.

\section{Uji Viskositas Formulasi Spray Antinyamuk}

Penentuan viskositas bertujuan untuk mengetahui adanya perubahan kekentalan pada tiap formula spray. Penentuan viskositas dilakukan dengan menggunakan viskometer Lamy Rheologi menggunakan spindel R-5 dengan kecepatan $50 \mathrm{rpm}$ selama 25 detik. Tolak ukur uji viskositas dalam penelitian ini adalah hasil viskositas dari $\mathrm{K}+($ Merek $\mathrm{X})$ dan pengujian ini dilakukakan selama 4 minggu.

Tabel 3. Hasil Uji Viskositas

\begin{tabular}{|c|c|c|c|c|c|c|}
\hline \multirow{2}{*}{ No. } & \multirow{2}{*}{ Formula } & \multicolumn{4}{|c|}{ Minggu Ke } & \multirow{2}{*}{$\begin{array}{r}\text { Rata- } \\
\text { rata }\end{array}$} \\
\hline & & 1 & 2 & 3 & 4 & \\
\hline 1 & $\mathrm{~F} 1$ & 53,22 & 54,33 & 55,43 & 49,36 & 53,08 \\
\hline 2 & $\mathrm{~F} 2$ & 51,02 & 31,44 & 39,44 & 48,81 & 42,67 \\
\hline 3 & F3 & 45,78 & 31,99 & 43,02 & 45,78 & 41,64 \\
\hline 4 & $\mathrm{~F} 4$ & 41,09 & 22,61 & 39,44 & 44,95 & 37,02 \\
\hline 5 & $\mathrm{~K}+$ & 33,64 & 28,68 & 40,81 & 44,12 & 36,82 \\
\hline
\end{tabular}

Pada tabel 3. di atas dapat dilihat rata-rata hasil uji viskositas dari F1-F4 yang menunjukkan bahwa $\mathrm{K}+$ memiliki hasil pengujian viskotas yang baik dengan nilai ratarata 36,82 dan yang kedua yaitu pada F4 dengan konsentrasi minyak atsiri serai wangi $15 \%$ yang memiliki nilai rata-rata 37,02 mendekati nilai rata-rata viskositas yang menjadi tolak ukur yaitu $\mathrm{K}+$ merek $\mathrm{X}$, penambahan minyak atsiri berpengaruh terhadap nilai viskositasnya.rata 36,82 yang mendekati nilai rata-rata $\mathrm{K}+($ Merek $\mathrm{X})$ yaitu 36,82 .

\section{Uji Pembentukkan Busa}

Uji pembentukkan busa juga menjadi salah satu parameter kualitas dari suatu larutan emulsi. Larutan emulsi yang baik tidak menghasilkan banyak busa saat dilakukan pengocokan ataupun pengadukan. Pengamatan busa stabil yang terjadi dilakukan saat larutan tersebut dikocok. Pengocokan Larutan dilakukan selama 1 menit kemudian tunggu sampai 3 menit, jika terjadi pembentukan busa maka perlu dilakukan perhitungan volume busa yang terbentuk, untuk menjadi tolak ukur dalam pengujian ini.

Tabel 4. Hasil Uji Pembentukan Busa

\begin{tabular}{lll} 
No & Formula & Volume Busa $(\mathbf{m L})$ \\
\hline 1 & F1 $(0 \%)$ & 0 \\
2 & F2 $(5 \%)$ & 0 \\
3 & F3 $(10 \%)$ & 0 \\
4 & F4 $(15 \%)$ & 0 \\
5 & K+ (Merek X) & 3 \\
\hline
\end{tabular}

Dari grafik diatas dapat dilihat bahwa pada seluruh formula tidak terbentuk busa sama sekali (Volume Busa $=0 \mathrm{ml}$ ). Produk pembanding yang digunakan dalam penelitian ini adalah sediaan merek $x$ dan produk ini memiliki stabilitas yang tidak begitu baik karena pada saat Uji Pembentukan busa terbentuk busa (Volume Busa $=3 \mathrm{ml}$ ) hal ini terjadi dikarenakan terdapat unsur keton pada senyawa yang terkandung didalam sediaan merek x. Maka dapat disimpulkan bahwa formulasi minyak atsiri serai wangi diatas memiliki stabilitas yang cukup baik karena tidak terjadi pembentukan busa.

\section{Uji Daya Tolak Nyamuk}

Pengujian efektivitas yang dilakukan adalah uji daya tolak (repelansi) terhadap nyamuk Culex s.p. Pengujian ini dilakukan berdasarkan Metode Standar Pengujian Efikasi Pestisida Untuk Pendaftaran yang dikeluarkan oleh Pusat Perizinan dan Investasi/Komisi Pestisida Departemen Pertanian Tahun 2007 Bidang Pengendalian Hama Pemukiman atau Rumah Tangga. Uji efikasi ditetapkan berdasarkan persen penolakan nyamuk terhadap lengan uji yang menggunakan produk antinyamuk spray, dan dibandingkan dengan lengan kontrol yang tidak menggunakan apapun (Arif Budi, 2011). 
Tabel 5. Uji Daya Tolak Nyamuk

\begin{tabular}{ccccccccc}
\hline & \multicolumn{7}{c}{ Uji Daya Proteksi ((k-r)/k)*100\% } & Rata-rata nyamuk \\
\cline { 2 - 7 } Formula & Jam ke-0 & Jam ke-1 & $\begin{array}{c}\text { Jam ke- } \\
\mathbf{2}\end{array}$ & Jam ke-3 & Jam ke-4 & Jam ke-5 & Jam ke-6 & yang tidak higgap \\
& $\mathbf{( \% )}$ & $\mathbf{( \% )}$ & $\mathbf{( \% )}$ & $\mathbf{( \% )}$ & $\mathbf{( \% )}$ & $\mathbf{( \% )}$ & $\mathbf{( \% )}$ & $\mathbf{( \% )}$ \\
\hline F1 & 61,11 & 8,33 & 21,43 & 35,71 & 28,57 & 8,33 & 46,67 & 30,02 \\
F2 & 75,00 & 70,59 & 61,11 & 43,75 & 43,75 & 33,33 & 25,00 & 50,36 \\
F3 & 78,95 & 86,36 & 83,33 & 80,95 & 75,00 & 41,67 & 61,11 & 72,48 \\
F4 & 100,00 & 100,00 & 90,48 & 85,00 & 78,95 & 80,95 & 75,00 & 87,20 \\
\hline K+ & 100,00 & 100,00 & 95,45 & 94,74 & 90,91 & 90,48 & 85,00 & 93,80 \\
\hline
\end{tabular}

Berdasarkan Tabel 5. dapat dilihat bahwa produk pembanding merek $x$ memiliki efektifitas penolakan nyamuk yang sangat baik, yaitu $93.80 \%$. Bila dibandingkan dengan hal tersebut, formula 4 (F4) memiliki efektifitas yang paling mendekati produk, karena F4 memiliki kosentrasi yang lebih tinggi di bandingkan dengan formula lainnya yaitu dengan persentase rataan $87.20 \%$.

Jika di bandingkan dengan kontrol positif spray minyak atsiri menunjukkan perbedaan yang jauh berbeda dimana kontrol positif menunjukkan hasil yang lebih baik, karena kontrol posotif yang digunakan mengandung DEET (diethylmetatoluamide), lebih efektif mengusir nyamuk dibanding dengan spray minyak atsiri, cara kerja DEET yaitu dengan memanipulasi bau dan rasa yang berasal dari kulit dengan menghambat reseptor pada antena nyamuk mencegah nyamuk mendeteksi kulit. Akan tetapi banyak bahaya dan efek samping yang ditimbulkan. Penggunaan DEET dalam dosis tinggi dan waktu yang lama dapat menyebabkan iritasi kulit, eritma (kemerahan pada kulit), kram otot, dan terbentuk ruam. Penggunaan berulang dan jangka waktu yang lama terabsorbsi melalui kulit dapat menyebabkan keracunan sistemik, hal ini sering terjadi pada anakanak(Santoso, 2009).

Bila dilihat dari kriteria minyak atsiri serai wangi sebagai daya tolak nyamuk yang telah disebutkan diatas dapat kita lihat bahwa efektifitasnya hanya mampu bertahan selama 4 jam dikarenakan sifat minyak atsiri serai wangi yang mudah menguap bila terlalu lama berhubungan dengan udara terbuka, karena minyak yang dihasilkan serai wangi tersebut adalah salah satu minyak atsiri atau minyak volatil (Zaki, 1998).

\section{KESIMPULAN}

Berdasarkan hasil penelitian yang telah dilakukan maka dapat disimpulkan bahwa :

1. Spray minyak atsiri serai wangi dari daun dan batang mempunyai efek sebagai antinyamuk Culex s.p.

2. Konsentrasi minyak atsiri dari daun dan batang serai wangi yang efektif sebagai spray antinyamuk yaitu pada formula 4 denngan konsetrasi minyak atsiri daun dan batang serai wangi $15 \%$ dengan hasil ratarata $87.20 \%$.

3. Dalam pengaruh variasi konsentrasi minyak atsiri terhadap sifat fisik spray

a) $\mathrm{Uji} \mathrm{pH}$ pada keempat formula spray minyak atsiri dari daun dan batang serai wangi.berpengaruh pada $\mathrm{pH}$ spray.

b) Uji viskositas dari keempat formula mempengaruhi viskositas pada sediaan spray dan perubahan nilai viskositasnya tidak terlalu besar.

c) Uji daya tolak nyamuk pada variasi konsentrasi dari keempat formula berpengaruh pada uji daya tolak nyamuk karena semakin tinggi konsentrasi minyak atsiri maka daya tolak terhadap nyamuk akan semakin baik.

\section{DAFTAR PUSTAKA}

Andriani, A. 2008. Uji Potensi Larvasida Fraksi Ekstrak Daun Cinacanthusnuntans $L$. Terhadap larva Instar III Nyamuk Aedes aegypti. institut Pertanian Bogor. Bogor.

Arief Budi Prasetyo. 2011. Formulasi Anti Nyamuk Spray Menggunakan Bahan Aktif Minyak Nilam. Fakultas Teknologi Pertanian. Institut Pertanian Bogor. Bogor

Dirtjen POM. 1979. Farmakope Indonesia. Edisi III. Departemen Kesehatan RI. Jakarta.

Kardinan \& Dhalimi. 2010. Potensi Adas (Foeniculum Vulgare) Sebagai Bahan 
Aktif Lotion Antinyamuk Demam Berdarah (Aedes aegypti). Bul. Litro, 21(1),61-68.).

Kardinan, Agus, MSC, APu, I. 2010. Mengenal Lebih Dekat Tanaman Pengusir Dan Pembasmi Nyamuk. Aromedia Pustaka. Jakarta.

R. , S. P., S, P. P., \& A., B. V. et al. 2014. Phytopharmacological Review of Plumeria species. Maharashtra. India.)

Rusli, Syahbana, Meika, D. 2010. Sukses Memproduksi Minyak Atsiri. Argomedia pustaka. Jakarta.)

Santoso, H. 2009. Analisis Bahaya DEET Pada Bahan Aktif Lotion Antinyamuk. Skripsi. Universitas Negeri Semarang. Semarang.

Sastrohamidjo. 2004. Kimia Minyak Atsiri. Yogyakarta: Gadjah Mada university Press.
Susanti \& Boesri. 2012. Toksisitas Biolarvasida Ekstrak Tembakau dibandinkan Dengan Ekstrak Zodia Terhadap Jentik Vektor Demam Berdarah Dengue. Buletin Penelitian Kesehatan, 40 (No.2).

Wahyunigtyas, D. 2004. Aktivitas Anti Bakteri Minyak Atsiri Daun Sirih Merah (Piper crocatum ruiz \& pav.) dan Minyak Atsiri Daun Sereh Wangi (Cymbopogon nardus (L.) rendle) Asal Tawangmangu Terhadap Bakteri Staphilococcus aureus dan Escherichia coli. Univ Muhammadyah Surakarta.

Zaki M, Z, Jantan I. 1998. Derivate of Environment-Friendly Insect Reppelents from The Leaf Oils of Selected Malaysian Plants. ASEAN Review of Biodiversity and Environment Coservation. Malaysia. 